\title{
Closure of oroantral fistula: a review of local flap techniques
}

\author{
Min-Soo Kwon, Baek-Soo Lee, Byung-Joon Choi, Jung-Woo Lee, Joo-Young Ohe, Jun-Ho Jung, \\ Bo-Yeon Hwang, Yong-Dae Kwon \\ Department of Oral and Maxillofacial Surgery, School of Dentistry, Kyung Hee University, Seoul, Korea
}

\begin{abstract}
J Korean Assoc Oral Maxillofac Surg 2020;46:58-65)
Oroantral fistula (OAF), also termed oroantral communication, is an abnormal condition in which there is a communicating tract between the maxillary sinus and the oral cavity. The most common causes of this pathological communication are known to be dental implant surgery and extraction of posterior maxillary teeth. The purpose of this article is to describe OAF; introduce the approach algorithm for the treatment of OAF; and review the fundamental surgical techniques for fistula closure with their advantages and disadvantages. The author included a thorough review of the previous studies acquired from the PubMed database. Based on this review, this article presents cases of OAF patients treated with buccal flap, buccal fat pad (BFP), and palatal rotational flap techniques.
\end{abstract}

Key words: Oroantral fistula, Buccal flap, Buccal fat pad, Palatal rotational flap

[paper submitted 2019. 12. 16 / revised 2020. 2. 3 / accepted 2020. 2. 3]

\section{Introduction and Definition of Oroantral Fistula}

Oroantral fistula (OAF) is an abnormal pathologic connection between the oral cavity and the maxillary sinus. This unfavorable event is usually associated with implant surgery, dental extraction, infection, sinusitis, osteomyelitis, trauma, and iatrogenic complications. Patients with this condition often experience unpleasant symptoms such as a reduced sense of smell and taste, pain in maxillary teeth, postnasal exudate, and halitosis ${ }^{1}$. Various treatments for OAF have been recommended in the literature. Visscher et al. ${ }^{2}$ broadly categorized the modalities of surgical treatment for the closure of OAF into autogenous soft tissue and bone grafts; allograft, xenograft, synthetic materials; and other techniques.(Fig. 1)

\footnotetext{
Yong-Dae Kwon

Department of Oral and Maxillofacial Surgery, School of Dentistry, Kyung Hee University, 26 Kyungheedae-ro, Dongdaemun-gu, Seoul 02447, Korea TEL: +82-2-958-9440 FAX: +82-2-958-4572

E-mail:kwony@khu.ac.kr

ORCID: https://orcid.org/0000-0001-9620-4814

(c) This is an open-access article distributed under the terms of the Creative Commons Attribution Non-Commercial License (http://creativecommons.org/ licenses/by-nc/4.0/), which permits unrestricted non-commercial use, distribution, and reproduction in any medium, provided the original work is properly cited.

Copyright (C) 2020 The Korean Association of Oral and Maxillofacial Surgeons. All rights reserved.
}

\section{Treatment of Different Manifestations of Oroantral Fistula}

Several aspects should be considered prior to choosing how to treat $\mathrm{OAF}$, including the size of the fistula tract, the time of diagnosis, and the presence of sinus infection ${ }^{2}$. In general, closure of the OAF within 48 hours of onset is recommended to avoid further complications. Spontaneous closure of the fistula may occur if the fistula is smaller than $3 \mathrm{~mm}$ in diameter. Suturing of the surrounding gingiva might be an efficient means by which to close the OAF in the case of a fistula measuring less than $5 \mathrm{~mm}$. Meanwhile, surgical treatment is usually recommended if the entrance of the fistula tract is larger than $5 \mathrm{~mm}$. If suturing alone is not enough to close the fistula, a flap procedure should be considered as an alternate treatment option ${ }^{2-4}$. However, proper infection control must be performed prior to closure of the fistula to prevent exacerbation of the infection if sinusitis is present.(Fig. 2,3)

In the case of patients with acute sinus infection, amoxicillin/clavulanate $1 \mathrm{~g} / 125 \mathrm{mg}$ three times per day for 10 to 14 days, nasal decongestants, and nonsteroidal anti-inflammatory drugs can be prescribed to manage the infection according to the recent literature 5 . The conduct of routine sinus irrigation could be helpful alongside the use of these medications. Meanwhile, patients with chronic sinus disease will require surgical intervention such as endoscopic sinus surgery (ESS) 


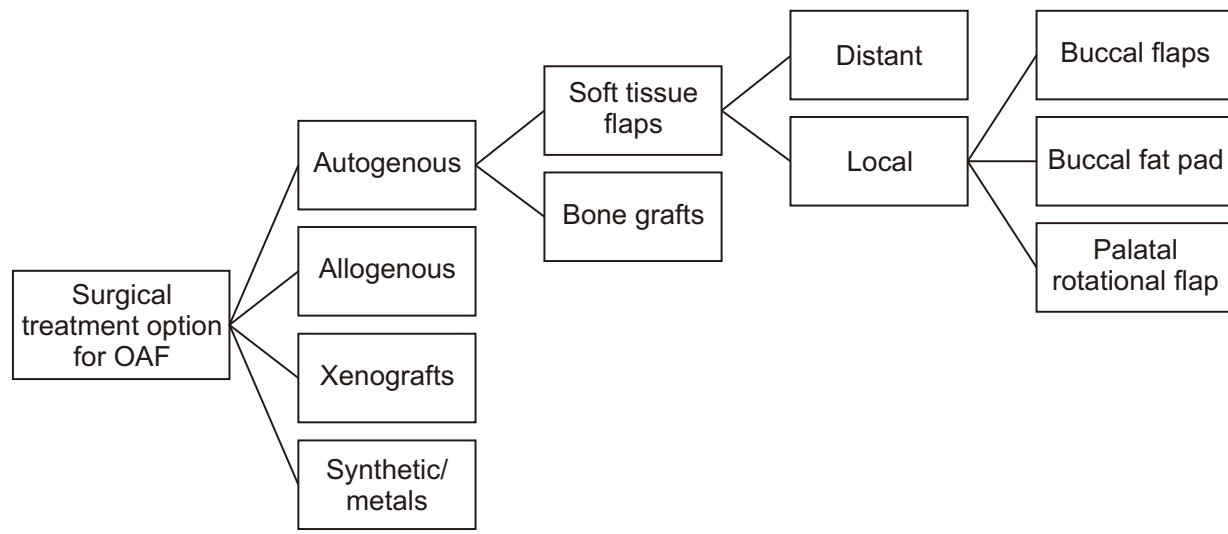

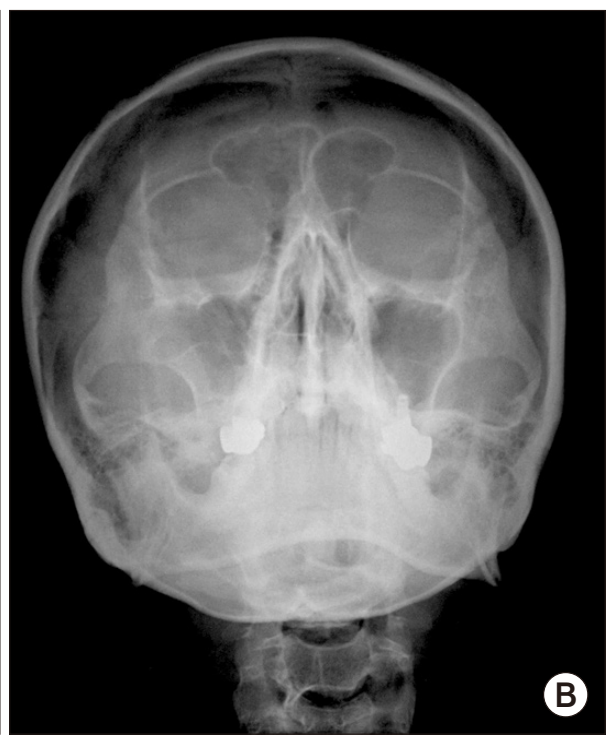

B
Fig. 1. Treatment modalities for oroantral fistula (OAF) closure. Modified from the article of Parvini et al. ${ }^{3}$ (Int $\mathrm{J}$ Implant Dent 2018;4:40) in accordance with the Creative Commons Attribution 4.0 International (CC BY 4.0) license.

Min-Soo Kwon et al: Closure of oroantral fistula: a review of local flap techniques. J Korean Assoc Oral Maxillofac Surg 2020
Fig. 2. A. Panorama shows a suspicious lesion at the extraction site of the posterior maxilla. B. Opacity of the right maxillary sinus is decreased on Waters' view due to the sinus infection.

Min-Soo Kwon et al: Closure of oroantral fistula: a review of local flap techniques. J Korean Assoc Oral Maxillofac Surg 2020
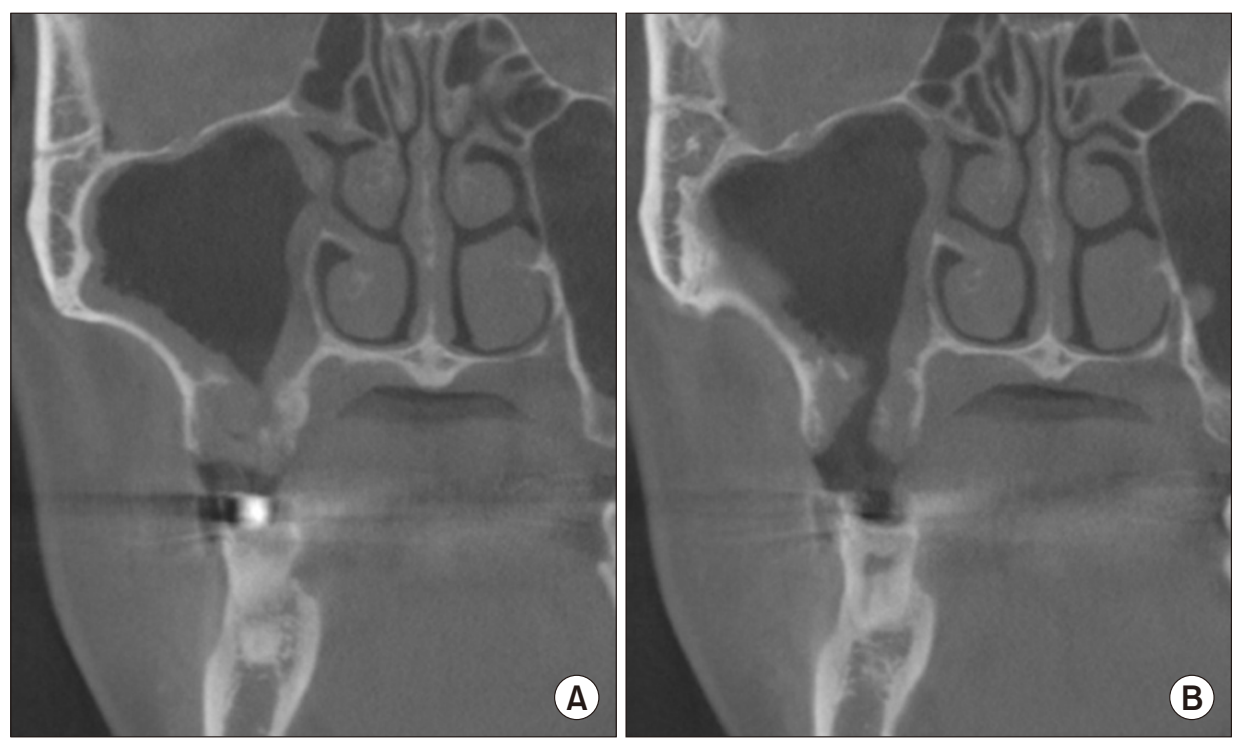

Fig. 3. Cone-beam computed tomography imaging confirms the connected tract $(A)$ and the sinus infection (B) on the right maxillary sinus.

Min-Soo Kwon et al: Closure of oroantral fistula: a review of local flap techniques. J Korean Assoc Oral Maxillofac Surg 2020 or the Caldwell-Luc procedure. The suggested algorithm for the treatment of OAF is illustrated in Fig. 4.

In the past few decades, an extensive pool of literature has developed pertaining to surgical closure of the OAF. Flap surgery techniques can be categorized into local and distant flaps. The most widely used local flap procedures include 
buccal flap, buccal fat pad (BFP), and palatal rotating flap. Distant flap procedures encompass tongue flap, auricular cartilage, and temporalis muscle flap.

This article seeks to provide an overview of the most widely accepted local flap procedures for OAF closure including their advantages and disadvantages. In addition, some cases of OAF patients are provided to suggest the effectiveness and current usage patterns of the techniques at the Department of Oral and Maxillofacial Surgery of Kyung Hee University School of Dentistry, Seoul, Korea. Complete closure of the OAF was achieved in all patients by using these local flap techniques. Additionally, reports related to OAF were identified in the PubMed database, focusing on the most commonly used local flap procedures, including buccal flap, BFP, and palatal rotational flap. Reference lists were examined to identify further relevant articles.

\section{Buccal Flaps}

Rehrmann $^{6}$ introduced buccal advancement flap, the most common and oldest surgical treatment for OAF closure, in 1936. This procedure involves the design of a broad-based trapezoid mucoperiosteal flap and its placement over the defect followed by sutures.(Fig. 5) Sufficient blood supply and, consequently, a high survival rate have been reported in the literature in relation to this technique ${ }^{7}$. However, this flap technique also presents the major disadvantage of that the buccal sulcus depth might decrease after the surgery, possibly resulting in reduced retention and increased discomfort among patients using dentures ${ }^{8}$. Some researchers have suggested that implant-overdentures could be an option to overcome this issue associated with a reduction in the buccal sulcus depth.

The buccal sliding flap introduced by Moczair is an alternative procedure for closing alveolar fistulae by shifting the flap distally, by about one tooth distance ${ }^{9}$. This flap technique
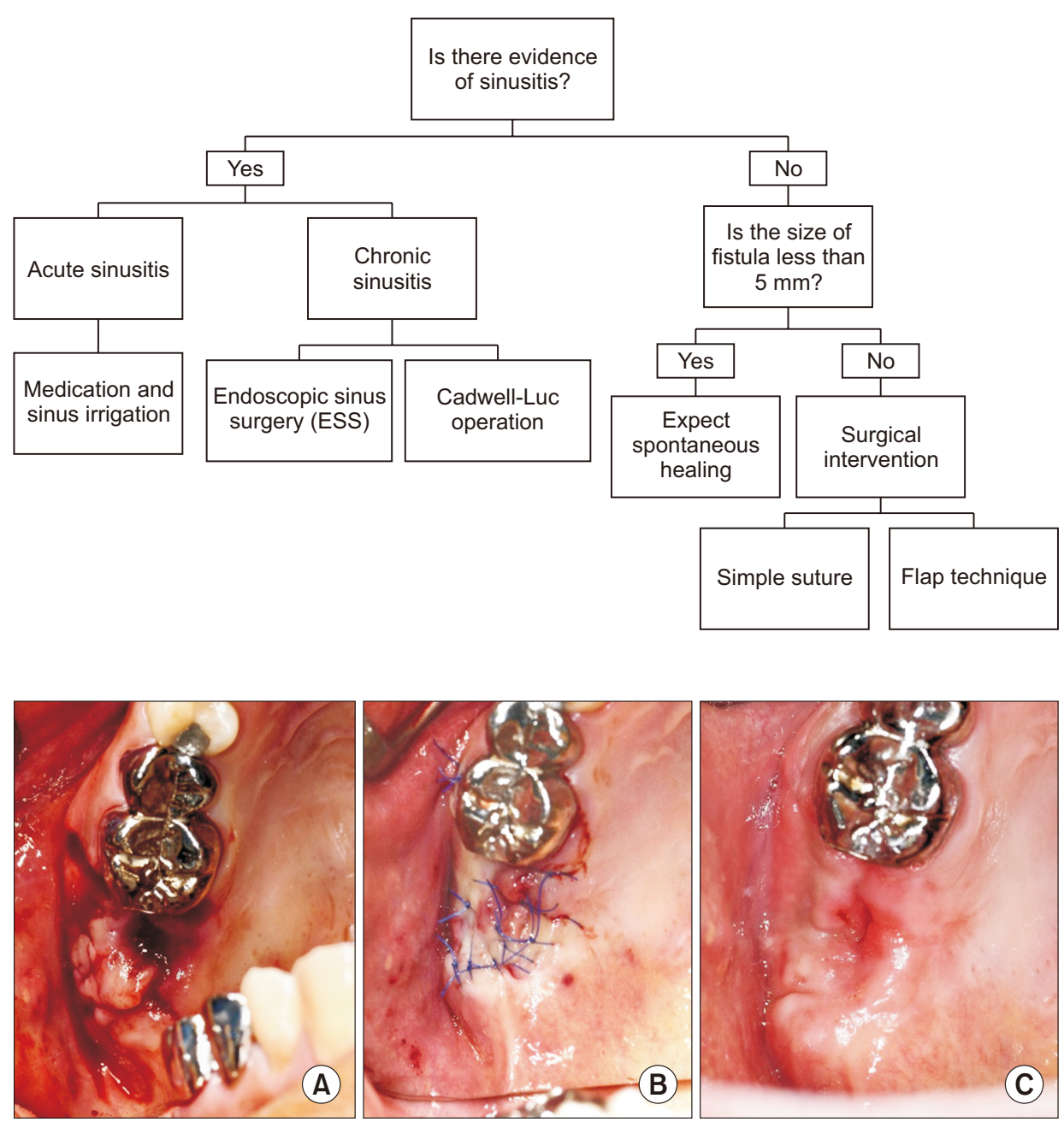

Fig. 4. Approach algorithm for the treatment of oroantral fistula.

Min-Soo Kwon et al: Closure of oroantral fistula: a review of local flap techniques. J Korean Assoc Oral Maxillofac Surg 2020

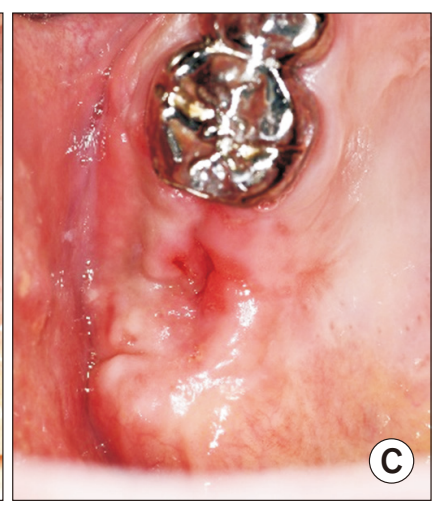

Fig. 5. A. shows a fistula the size of a single tooth on the second premolar region of the maxilla. $B$. The buccal sliding flap covering over the fistula and sutured with the palatal mucosa can be seen. C. Complete healing was obtained at three weeks after the surgery. Min-Soo Kwon et al: Closure of oroantral fistula: a review of local flap techniques. J Korean Assoc Oral Maxillofac Surg 2020 
has the advantage of that the influence of buccal sulcus depth is minimal. However, it may provoke the onset of periodontal disease and gingival recession because of its need for a significant amount of dentogingival detachment.

\section{Buccal Fat Pad}

The BFP, a lobulated form of fatty tissue enclosed by a thin fibrous capsule, is eligible as an alternative for the closure of $\mathrm{OAF}^{10-12}$. Along with other reconstruction procedures in oral surgery, Egyedi ${ }^{13}$ first described the use of BFP as a pedicled graft for the closure of OAF. The BFP acquires its blood supplies from the buccal and deep temporal branches of the maxillary artery, the transverse branch of the superficial temporal artery, and branches of the facial artery. Harvesting of the BFP can be conducted by way of a vestibular incision in the maxillary tuberosity area, followed by blunt dissection under the periosteum of the buccal flap and gentle traction of the fat to the recipient site $^{14}$.

The advantages of using the BFP as a graft material include the great ability of utilization, nourishing blood supply, and negligible donor-site morbidity ${ }^{15,16}$. The technique does not greatly affect the buccal sulcus depth and requires complete coverage by the oral mucosa. The aforementioned rich blood supply enables the uncovered fat to epithelize by itself within two weeks after the surgery ${ }^{17}$. According to the literature, the exposed BFP appears to undergo complete epithelialization within four to six weeks.

Despite these advantages, the BFP may show graft necrosis and new fistulae when used for the closure of large defects. Additionally, the conduct of this flap technique requires very careful manipulation. Hence, the surgeon's experience and competence should be taken into account in the decisionmaking process about which technique to adopt ${ }^{18}$. Another consideration to be taken into account with this approach is the patient's history of radiation therapy before conducting the procedure because the size and mobility of the fat pad could be affected by the degree of prior radiation. It is well-established that radiation therapy in head and neck cancer patients is often correlated with complications including mucositis, desquamation of the skin, dysphagia, xerostomia, and cytotoxic damage to the salivary glands. Similarly, injury to the BFP seems to be inevitable following radiation therapy of the head and neck, resulting in decreased mobility and size of the $\mathrm{BFP}^{19-22}$. In a recent study, the use of double-layered suturing with the BFP and oral mucosa is recommended to minimize the chance of postoperative complications ${ }^{23}$.(Fig. 6. D)

\section{Palatal Rotational Flap}

Another well-known and widely used procedure for the closure of large OAFs is the palatal-based rotational flap ${ }^{24}$. Palatal flaps can be classified by their thickness and direction of movement. OAFs larger than $10 \mathrm{~mm}$ or that are undergo-
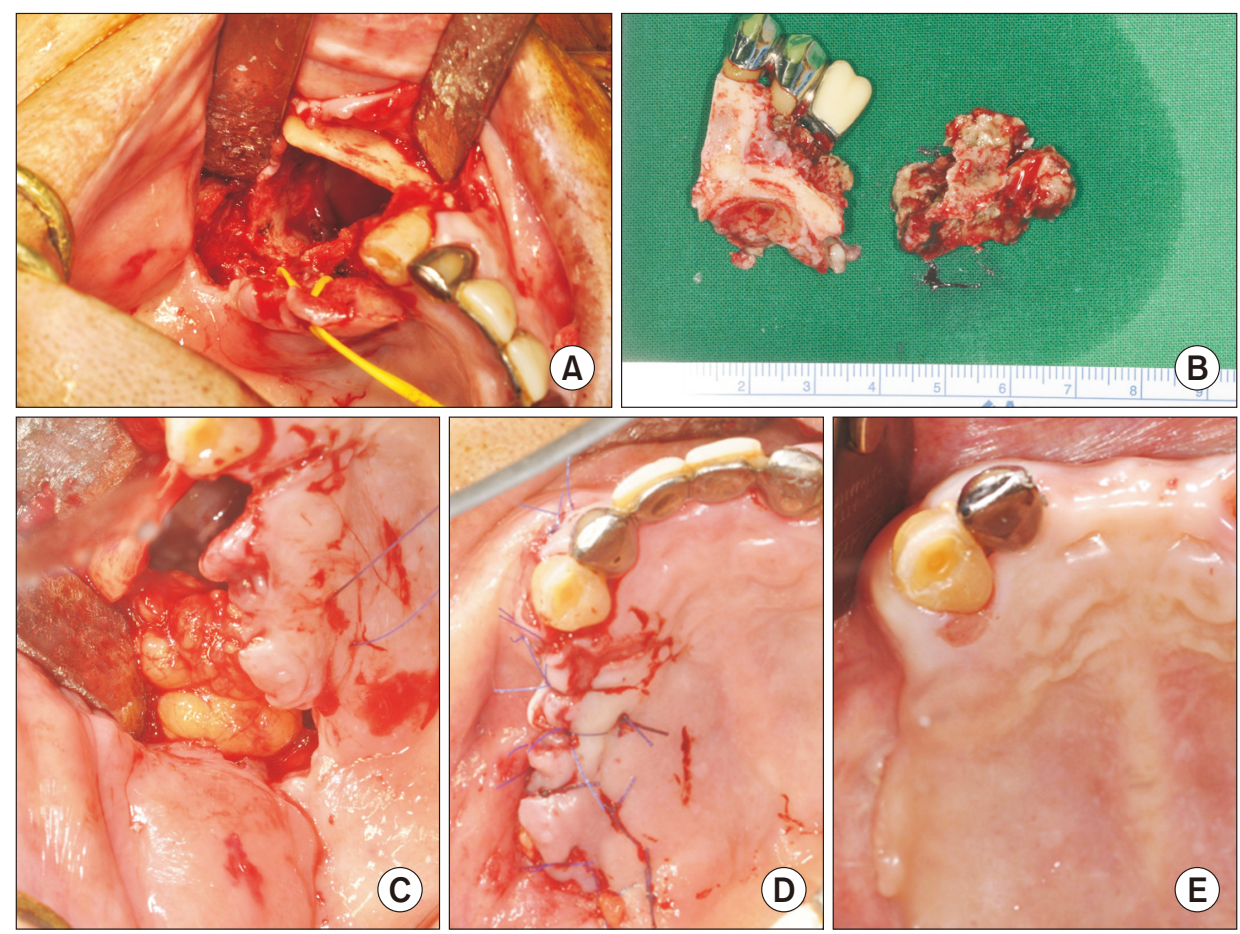

Fig. 6. A, B. Partial maxillectomy was performed to remove the necrotic region of the maxilla. C. Harvest of the abundant amount of the buccal fat pad (BFP). D. The defect was covered with the BFP and oral mucosa by doublelayered suture. E. Complete healing was observed, and no signs of complications were noted at 11 weeks after the surgery.

Min-Soo Kwon et al: Closure of oroantral fistula: a review of local flap techniques. J Korean Assoc Oral Maxillofac Surg 2020 
ing late repair usually require full-thickness mucoperiosteal rotating palatal flaps ${ }^{25,26}$. This procedure may necessitate that a circular excision of the fistula tract is established as it is often larger than it appears at the entrance.(Fig. 7) It is essen- tial to include the greater palatine artery for sufficient blood supply during the flap harvesting step $^{27}$. Secondary wound healing (epithelialization) is expected to occur at the exposed palatal bone of the donor site within two weeks.
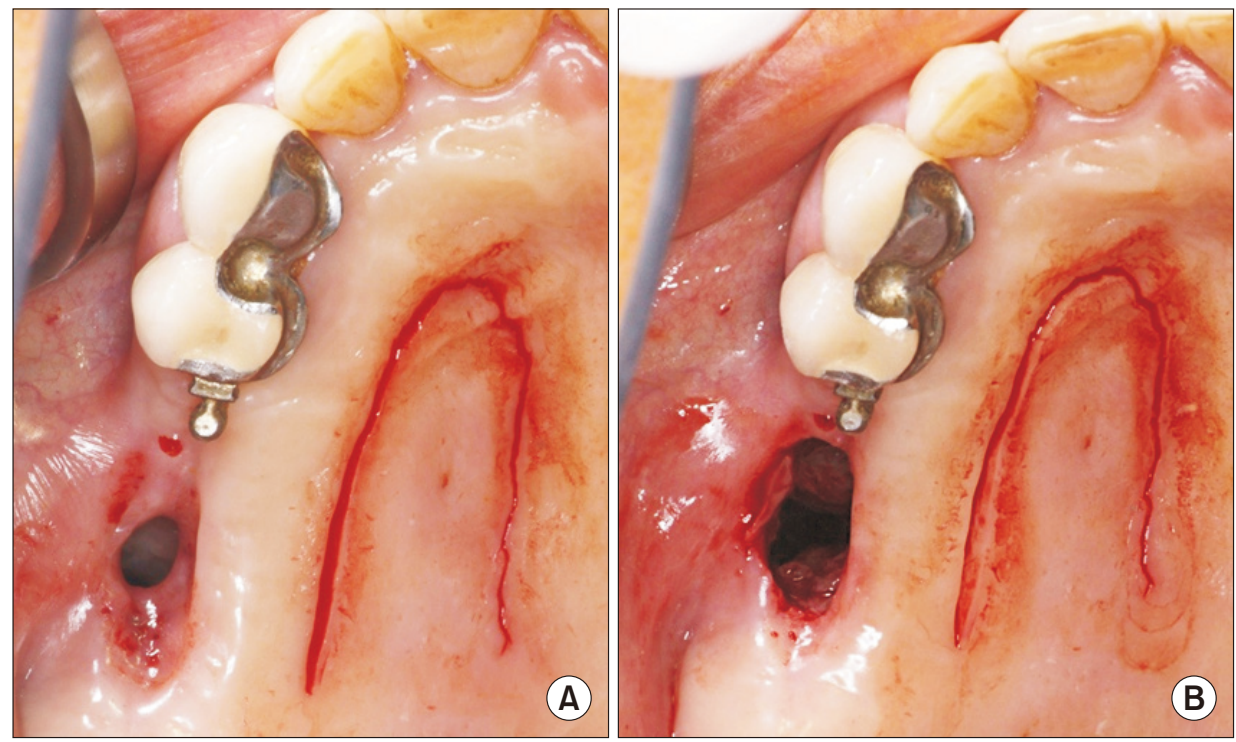

Fig. 7. A, B. Circular excision of the fistula tract reveals a larger entrance than as suggested from the outside.

Min-Soo Kwon et al: Closure of oroantral fistula: a review of local flap techniques. J Korean Assoc Oral Maxillofac Surg 2020
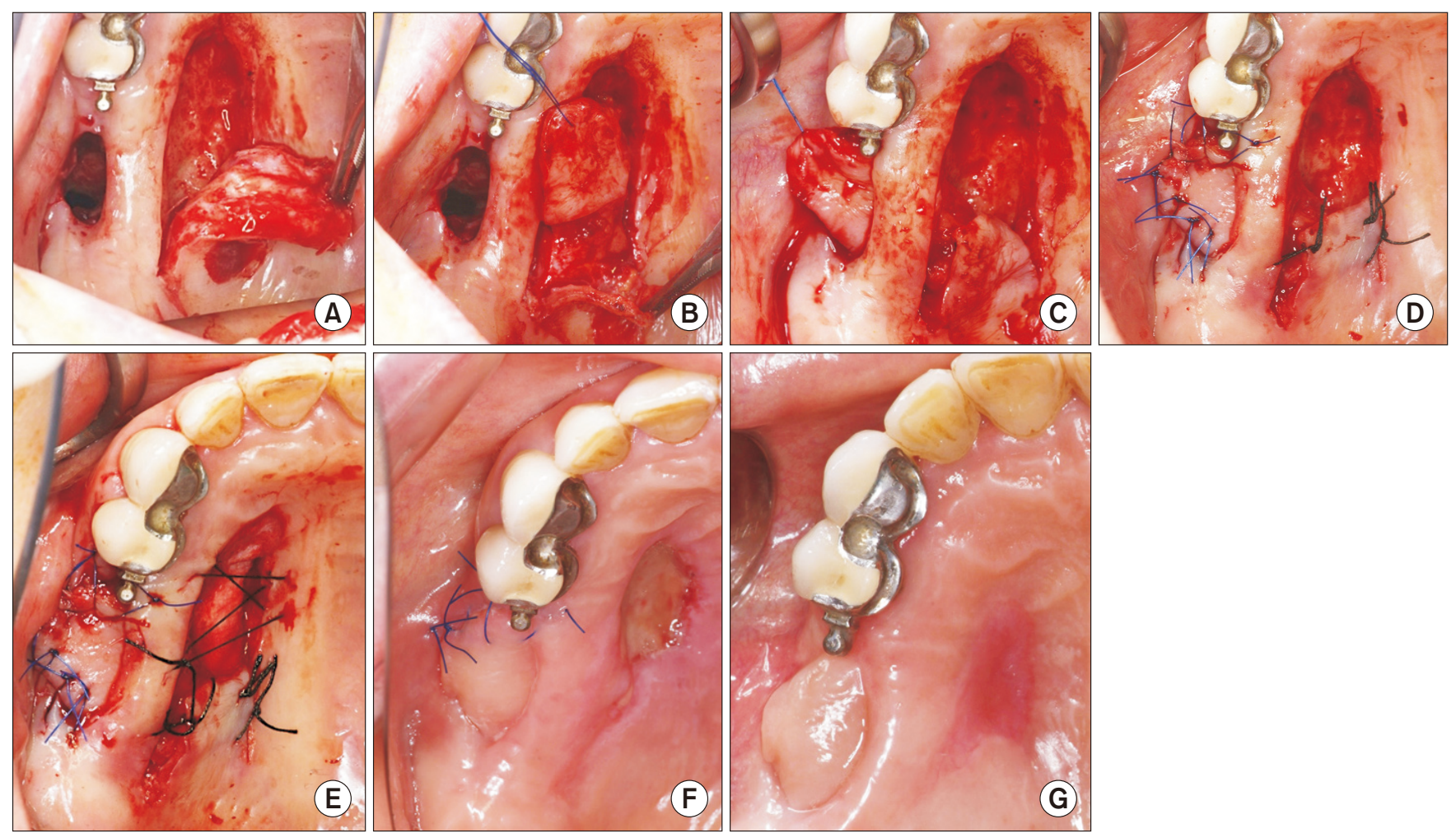

Fig. 8. A. Full-thickness palatal harvest includes the greater palatine artery. B. Subepithelial dissection of the rotating region of the flap. C. The flap was rotated and placed through the fistula tract underneath the tunnel. D. The flap was sutured to the remaining buccal mucosa and, also, the rotated area of the flap was sutured to limit undesired movement of the flap during the healing period. E. The collagen sponge was used to cover the denuded donor site. F. The secondary wound healing of the donor site can be seen. G. Complete healing without complications was observed at two months of follow-up.

Min-Soo Kwon et al: Closure of oroantral fistula: a review of local flap techniques. J Korean Assoc Oral Maxillofac Surg 2020 
The advantage of this flap technique makes it more preferable relative to buccal flaps in case a certain level of the buccal vestibule depth needs to be preserved. Moreover, inclusion of the greater palatine artery secures a certain amount of the thickness of the flap and makes it less vulnerable to breaking down ${ }^{28}$. These are the most important advantages of the palatal rotational flap technique (i.e., sufficient vascularization and exceptional thickness). Palatal splint or suturing with collagen sponge material can be completed to enhance the secondary epithelialization of the exposed donor site.

The primary challenge that clinicians may encounter during flap manipulation is the stiffness of the palatal flap. Since the palatal rotational flap necessarily includes the greater palatine artery, the thickness of the flap limits its ability to be rotated. Therefore, conducting subepithelial dissection of the connective tissue on the rotating region is advised to release the tension, avoid the twist of the artery, and limit possible necrosis of the flap.(Fig. 8. B, 8. C)

\section{Summary and Discussion}

Patients with OAF often experience abnormal discomfort along with postnasal exudate and halitosis following extraction or implant surgery in the posterior area of the maxilla. If OAF is suspected, a thorough clinical examination and evaluation should be proceeded with. Radiographic examinations such as panoramic view and Waters' view allow us to see the presence of sinus infection. The connection between the oral cavity and maxillary sinus can be confirmed with conebeam computed tomography. Once the OAF is confirmed, clinicians may follow the suggestive algorithm to establish the treatment plan. If there is evidence of sinus infection, infection control should be made a priority before any surgical intervention. The fistula tract itself can act as a drainage route so patients may not experience any symptoms that possibly exacerbate the development of sinus infections and symptoms after fistula closure. A thorough evaluation and infection control protocol must be deployed for this reason. In the case of acute sinusitis, the infection could be managed with medication and sinus irrigation. A recent study reported a novel method of infection control in patients with acute maxillary sinusitis occurring after sinus grafting ${ }^{29}$. The authors explained that routine saline irrigation along with medication was enough to resolve the complication in the case of acute sinusitis. ESS and the Caldwell-Luc operation could be performed before OAF closure if the infection is severe in the presence of chronic sinusitis.
With fistulae smaller than $3 \mathrm{~mm}$ in diameter, spontaneous healing could be anticipated as long as any sinus infection is successfully managed. Surgical intervention should be considered if the size of the fistula is larger than $5 \mathrm{~mm}$. Many surgical methods have been suggested to achieve the resolution of OAF. The majority of prior research has indicated successful results can be achieved by using buccal flap, BFP, and palatal rotational flap techniques. Buccal flap techniques offer the advantage of nearness of the harvesting area to the defected area. Despite the possibility of a decrease in sulcus depth, its ease of use and proximity to the recipient site make it a preferred procedure among clinicians when they encounter patients with small OAFs.

As a very effective flap procedure, the BFP technique offers many advantages. Among these, the rich blood supply of the BFP from different arteries in the facial region makes it less vulnerable and highly useful in the repair of OAF. As previously shown in Fig. 6, the BFP can be used to repair large defects when it is covered and sutured with the oral mucosa as a double layer. This capacity of the BFP increases the chance of achieving successful primary healing after procedures like partial maxillectomy. However, clinicians should be cautious when using the BFP among OAF patients who received previous radiation therapy in the head and the neck area. Many studies support that patients with cancer of the head and neck often experience radiotherapy-induced side effects; for example, salivary flow tends to decrease due to cytotoxic damage to the salivary glands. It is believed that a similar injury to the vascular supply of the BFP can cause decreased mobility and size. Therefore, alternative methods might be preferable if the patient has a history of radiation therapy in the facial area.

Some authors have postulated that the palatal flap approach should be used preferably for OAFs measuring larger than $10 \mathrm{~mm}^{30}$. Full-thickness palatal rotational flaps including the greater palatine artery facilitate the repair of larger defects. Another advantage of this flap technique is the abundant amount of keratinized mucosa achieved that can assist with outcomes of a future implant surgery by providing support in the region ${ }^{31,32}$. The stiffness of the flap may be inconvenient when clinicians try to rotate the flap toward the defected area, but this can be resolved by subepithelial dissection.

Although each flap technique has its benefits and drawbacks, it has been shown that these techniques are successful when they were used with proper indications. For this reason, clinicians should be competent and well aware of the various treatment options available for closure of OAFs. In addition, 
certain factors must be taken into account when establishing the treatment plan; specific needs and the medical history of the patient such as the use of dentures and a history of radiation therapy in the head and neck region must be taken into account. Therefore, the quantity and quality of remaining tissue should be thoroughly evaluated along with the possibility of further implant placement in the affected site. Finally, a recent study states that the Valsalva test, cheek-blowing test, and probing of the perforated site may help the diagnosis process; however, these examinations should be performed with caution because small perforations may not be detected and thus may result in antral complications or widening of the fistula tract.

\section{ORCID}

Min-Soo Kwon, https://orcid.org/0000-0001-7956-0462

Baek-Soo Lee, https://orcid.org/0000-0002-9145-8062

Byung-Joon Choi, https://orcid.org/0000-0002-6644-7994

Jung-Woo Lee, https://orcid.org/0000-0001-9902-347X

Joo-Young Ohe, https://orcid.org/0000-0002-4411-7871

Jun-Ho Jung, https://orcid.org/0000-0002-7007-0974

Bo-Yeon Hwang, https://orcid.org/0000-0001-7254-3141

Yong-Dae Kwon, https://orcid.org/0000-0001-9620-4814

\section{Authors' Contributions}

M.S.K. participated in data collection and wrote the manuscript. B.S.L., B.J.C., J.W.L., J.Y.O., J.H.J., and B.Y.H. participated in the study design. Y.D.K. treated the patients and participated in the study coordination and helped to draft the manuscript. All authors read and approved the final manuscript.

\section{Conflict of Interest}

No potential conflict of interest relevant to this article was reported.

\section{References}

1. Yalçın S, Oncü B, Emes Y, Atalay B, Aktaş I. Surgical treatment of oroantral fistulas: a clinical study of 23 cases. J Oral Maxillofac Surg 2011;69:333-9.

2. Visscher SH, van Minnen B, Bos RR. Closure of oroantral communications: a review of the literature. J Oral Maxillofac Surg 2010;68:1384-91.

3. Parvini P, Obreja K, Sader R, Becker J, Schwarz F, Salti L. Surgi- cal options in oroantral fistula management: a narrative review. Int J Implant Dent 2018;4:40.

4. Dym H, Wolf JC. Oroantral communication. Oral Maxillofac Surg Clin North Am 2012;24:239-47, viii-ix.

5. Hernando J, Gallego L, Junquera L, Villarreal P. Oroantral communications. A retrospective analysis. Med Oral Patol Oral Cir Bucal 2010;15:e499-503.

6. Rehrmann A. [Eine methode zur schliessung von kieferhöhlenperforationen]. Dtsch Zahnärztl Wschr 1936;39:1136-8. German.

7. Killey HC, Kay LW. Observations based on the surgical closure of 362 oro-antral fistulas. Int Surg 1972;57:545-9.

8. von Wowern N. Closure of oroantral fistula with buccal flap: Rehrmann versus Môczár. Int J Oral Surg 1982;11:156-65.

9. Haanaes HR, Pedersen KN. Treatment of oroantral communication. Int J Oral Surg 1974;3:124-32.

10. Martín-Granizo R, Naval L, Costas A, Goizueta C, Rodriguez F, Monje F, et al. Use of buccal fat pad to repair intraoral defects: review of 30 cases. Br J Oral Maxillofac Surg 1997;35:81-4.

11. el-Hakim IE, el-Fakharany AM. The use of the pedicled buccal fat pad (BFP) and palatal rotating flaps in closure of oroantral communication and palatal defects. J Laryngol Otol 1999;113:834-8.

12. Rapidis AD, Alexandridis CA, Eleftheriadis E, Angelopoulos AP. The use of the buccal fat pad for reconstruction of oral defects: review of the literature and report of 15 cases. J Oral Maxillofac Surg 2000;58:158-63.

13. Egyedi P. Utilization of the buccal fat pad for closure of oro-antral and/or oro-nasal communications. J Maxillofac Surg 1997;5:241-4.

14. Arce K. Buccal fat pad in maxillary reconstruction. Atlas Oral Maxillofac Surg Clin North Am 2007;15:23-32.

15. Stajcić $Z$. The buccal fat pad in the closure of oro-antral communications: a study of 56 cases. J Craniomaxillofac Sur 1992;20:1937.

16. Baumann A, Ewers R. Application of the buccal fat pad in oral reconstruction. J Oral Maxillofac Surg 2000;58:389-92; discussion 392-3.

17. Yang S, Jee YJ, Ryu DM. Reconstruction of large oroantral defects using a pedicled buccal fat pad. Maxillofac Plast Reconstr Surg 2018;40:7.

18. Parvini P, Obreja K, Begic A, Schwarz F, Becker J, Sader R, et al. Decision-making in closure of oroantral communication and fistula. Int J Implant Dent 2019;5:13.

19. Paterson C, Thomson MC, Caldwell B, Young R, McLean A, Porteous $\mathrm{S}$, et al. Radiotherapy-induced xerostomia: a randomised, double-blind, controlled trial of Visco-ease ${ }^{\mathrm{TM}}$ oral spray compared with placebo in patients with cancer of the head and neck. Br J Oral Maxillofac Surg 2019;57:1119-25.

20. Dirix P, Nuyts S, Van den Bogaert W. Radiation-induced xerostomia in patients with head and neck cancer: a literature review. Cancer 2009;107:2525-34.

21. Dirix P, Nuyts S, Vander Poorten V, Delaere P, Van den Bogaert W. The influence of xerostomia after radiotherapy on quality of life: results of a questionnaire in head and neck cancer. Support Care Cancer 2008;16:171-9.

22. Vissink A, Mitchell JB, Baum BJ, Limesand KH, Jensen SB, Fox $\mathrm{PC}$, et al. Clinical management of salivary gland hypofunction and xerostomia in head-and-neck cancer patients: successes and barriers. Int J Radiat Oncol Biol Phys 2010;78:983-91.

23. Tideman H, Bosanquet A, Scott J. Use of the buccal fat pad as a pedicled graft. J Oral Maxillofac Surg 1986;44:435-40.

24. Wells DL, Capes JO. Complications of dentoalveolar surgery. In: Fonseca RJ, ed. Oral and maxillofacial surgery. Philadelphia: WB Saunders; 2000:432.

25. Ehrl PA. Oroantral communication. Epicritical study of 175 patients, with special concern to secondary operative closure. Int J Oral Surg 1980;9:351-8.

26. Anavi Y, Gal G, Silfen R, Calderon S. Palatal rotation-advancement flap for delayed repair of oroantral fistula: a retrospective evalua- 
tion of 63 cases. Oral Surg Oral Med Oral Pathol Oral Radiol Endod 2003;96:527-34.

27. Jamali JA. Palatal flap. Oral Maxillofac Surg Clin North Am 2014;26:305-11.

28. Ward BB. The palatal flap. Oral Maxillofac Surg Clin North Am 2003; $15: 467-73$, v.

29. Hong SO, Shim GJ, Kwon YD. Novel approach to the maxillary sinusitis after sinus graft. Maxillofac Plast Reconstr Surg 2017;39:18.

30. Er N, Tuncer HY, Karaca C, Copuroğlu S. Treatment of oroantral fistulas using bony press-fit technique. J Oral Maxillofac Surg 2013;71:659-66.

31. Lin GH, Chan HL, Wang HL. The significance of keratinized mucosa on implant health: a systematic review. J Periodontol
2013;84:1755-67.

32. Brito C, Tenenbaum HC, Wong BK, Schmitt C, Nogueira-Filho G. Is keratinized mucosa indispensable to maintain peri-implant health? A systematic review of the literature. J Biomed Mater Res B Appl Biomater 2014;102:643-50.

How to cite this article: Kwon MS, Lee BS, Choi BJ, Lee JW, Ohe JY, Jung JH, et al. Closure of oroantral fistula: a review of local flap techniques. J Korean Assoc Oral Maxillofac Surg 2020;46:58-65. https://doi.org/10.5125/jkaoms.2020.46.1.58 